\title{
Changes of the smooth endoplasmic reticulum induced by rifampicin in human and guinea-pig hepatocytes ${ }^{1}$
}

\author{
A. M. JEZEQUEL, F. ORLANDI, AND L. T. TENCONI
}

From the Centre for the Study of the Action of Drugs on the Liver, University of Camerino, and the Division of Gastroenterology, the General Hospital, Ancona, and the Research Laboratories, Gruppo Lepetit S.p.A., Milan, Italy

SUMMARY Rifampicin induces a proliferation of the smooth endoplasmic reticulum in guinea-pig and human hepatocytes. This may support the hypothesis of enhancement of drug-metabolizing enzymes induced by the drug. However, the pattern of proliferation is not similar in man and in guinea-pig hepatocytes. Some caution is needed in the study of enzyme induction in man and in extrapolations from animal to human data.

The rifamycins are largely used for therapeutic purposes, and, as well as antibiotic properties, they have demonstrated various effects at the level of the liver. An effect on the excretion of bilirubin, bromsulphalein, and contrast media has been shown after both rifamycin SV (Acocella and Billing, 1965; Acocella, Nicolis, and Tenconi, 1965) and rifampicin (Keberle, Schmid, and Meyer-Brunot, 1968; Curci, Ninni, and Iodice, 1969). On the other hand, repeated administration of rifampicin causes a decrease in the half-life and a fall in blood levels of the drug (Curci, Ninni, and Iodice, 1969; Furesz, 1970) together with an increase in biliary excretion of the antibiotic (Furesz, 1970). The latter findings were suggestive of a self-induced enhancement of rifampicin metabolism, and studies were undertaken to define the morphological changes eventually occurring during therapy with the antibiotic. Parallel studies have been conducted on human and guineapig liver.

\section{Material and Methods}

\section{GUINEA-PIGS}

Seventeen females, aged 45-50 days and weighing from 310 to $350 \mathrm{~g}$, were studied and grouped as follows.

Eleven animals received $80 \mathrm{mg} / \mathrm{kg}$ rifampicin

'Part of this work was supported by research contract no. 70.-01927-04 from the CNR, Rome.

Received for publication 17 September 1971. suspended in $1 \%$ Methocel at a concentration of $16 \mathrm{mg} / \mathrm{ml}$ through a gastric tube. After two days of treatment three animals, after five days five, and after 10 days three animals were killed.

Four animals received only $1 \%$ Methocel at a dose of $0.5 \mathrm{ml} / 100 \mathrm{~g}$ body weight: at two days one was killed, at five days two,and at 10 days one animal.

Two animals did not receive any treatment.

These animals were killed by section of the carotid; the abdomen was opened immediately and fragments of liver were processed for light and electron microscopy.

\section{PATIENTS}

Two patients received $20 \mathrm{mg} / \mathrm{kg} /$ day rifampicin (Rifadin, Lepetit-Milan) and four $10 \mathrm{mg} / \mathrm{kg} /$ day. A liver biopsy was taken after two days of treatment. A control biopsy before treatment was obtained in three of these patients.

One patient received $10 \mathrm{mg} / \mathrm{kg} /$ day for five days followed by $16 \mathrm{mg} / \mathrm{kg} /$ day for two days. A liver biopsy was taken at the end of the seven days.

\section{PROCESSING THE MATERIAL}

For light microscopy fragments of liver were fixed in $4 \%$ formalin, embedded in paraffin, and stained with haematoxylin-eosin. For electron microscopy, $1 \mathrm{~mm}^{3}$ fragments were fixed for one and a half hours in $1 \%$ osmic acid in phosphate buffer $p \mathrm{H} \mathrm{7.4.} \mathrm{After}$ dehydration with alcohol the fragments were embedded in an Epon/Araldite mixture.

The blocks were cut with an LKB Ultrotome III 
and the sections examined with an electron microscope (Hitachi HS-7).

\section{Results}

No structural modification was observed with the light microscope after treatment with rifampicin either in man or in guinea-pig liver. With the electron microscope, modifications were observed, especially at the level of the endoplasmic reticulum of hepatocytes.

\section{GUINEA-PIGS}

In normal guinea-pig liver the rough endoplasmic reticulum appears as slightly dilated cisternae. The smooth endoplasmic reticulum is in the form of small irregular vesicles occupying limited areas of the cytoplasm. It is always associated with rosettes of glycogen.

After two days of treatment almost all hepatocytes showed an increase in the amount of smooth endoplasmic reticulum in various limited areas of the cytoplasm. Moreover the vesicles of the smooth endoplasmic reticulum took a tubular form and were more uniform in size than in untreated animals.

After five days the increase in amount of smooth endoplasmic reticulum was even more evident and all hepatocytes were involved. The area occupied by it represented one fourth to one half of a cell section. The tubular elements made a dense network and rosettes of glycogen were frequently seen in the meshes (Fig. 1). The cisternae of the rough endoplasmic reticulum were often dilated and numerous ribosomes and polysomes were present.

After 10 days large areas occupied by the smooth endoplasmic reticulum were still visible and in some cells the densely packed smooth endoplasmic reticulum had a felty appearance. The rough endoplasmic reticulum remained unchanged. Modifications at the level of the space of Disse or of the biliary canaliculi were not observed at any stage.

No differences were noted between untreated animals and animals receiving Methocel only.

\section{HUMAN LIVER}

In the hepatocytes of normal human liver the rough

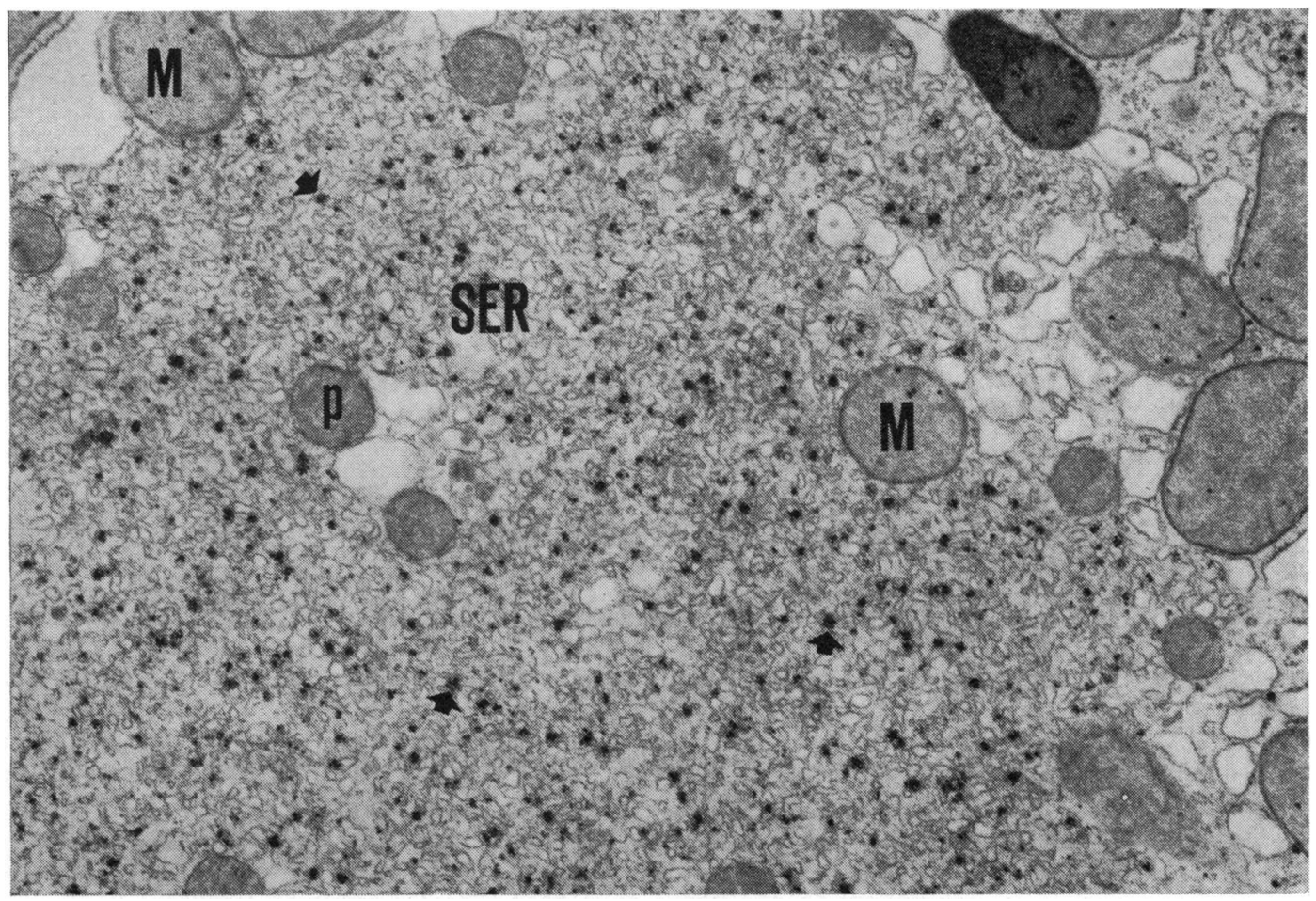

Fig. 1 Liver of guinea-pig treated for five days with rifampicin. Vast areas of the cytoplasm are occupied by the proliferated smooth endoplasmic reticulum. The reticulum has a finely tubular appearance (SER) and numerous rosettes of glycogen are seen in the meshes of the network (arrows). $M=$ mitochondria; $p=$ peroxisomes. $\times 18,800$. 


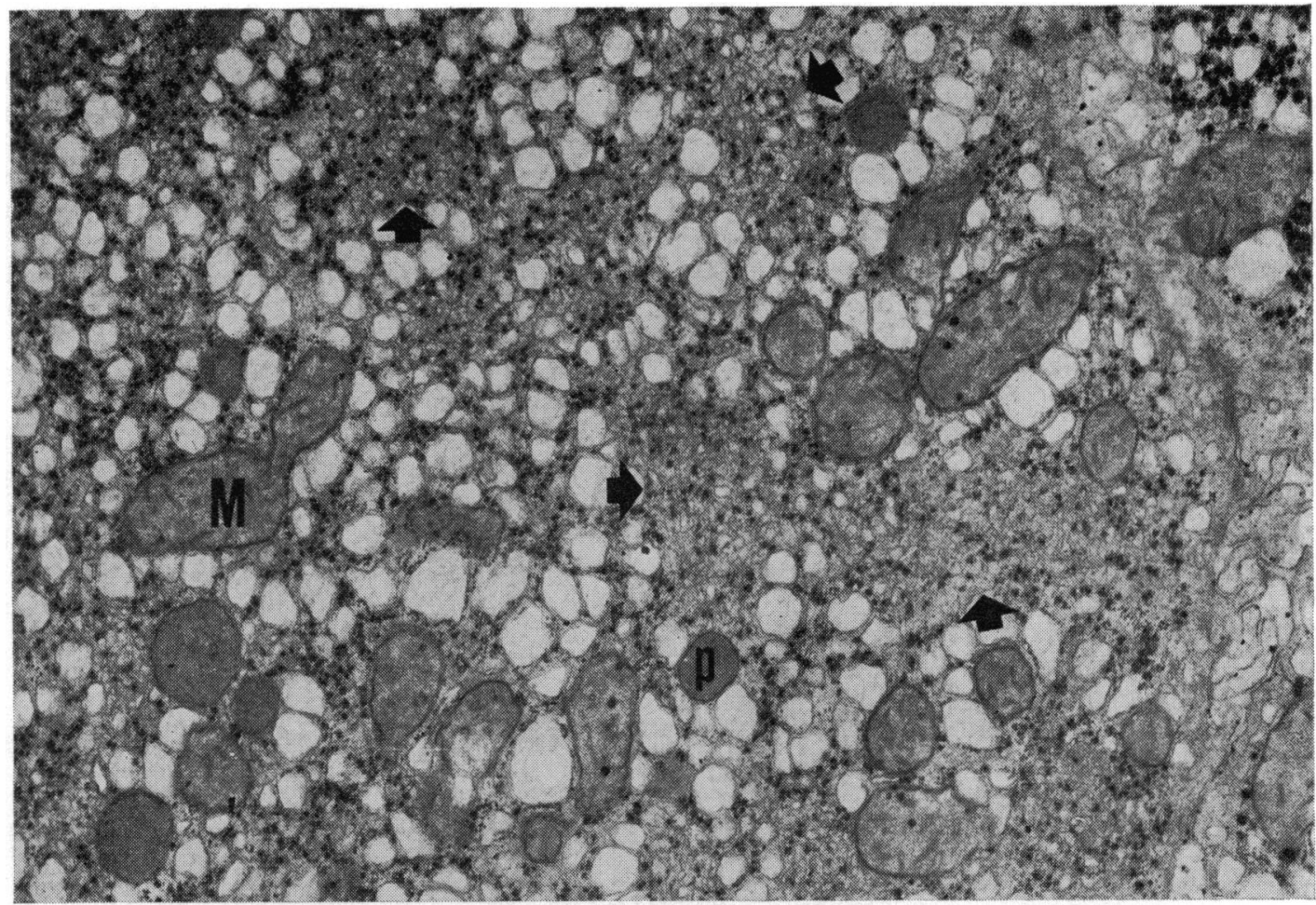

Fig. 2 Human liver after two days of treatment with rifampicin $(20 \mathrm{mg} / \mathrm{kg} /$ day). Large vesicles of smooth endoplasmic reticulum are visible alternating with islets where small vesicles and tubules are densely packed (arrows) together with rosettes of glycogen. For comparison, the enlargement is similar to that of Figure 1. The different pattern in the proliferation of smooth endoplasmic reticulum in man and in guinea-pig is evident. $\times 18,800$.

endoplasmic reticulum is in the form of a few, generally dilated, cisternae. The smooth endoplasmic reticulum has a finely vesicular appearance and is more diffusely distributed than in rat or in guinea-pig liver.

After two days of treatment with rifampicin the distribution of the smooth endoplasmic reticulum was modified in many hepatocytes: next to areas of apparently normal smooth endoplasmic reticulum, dense islets were present, due to the concentration of vesicles and tubules of the smooth endoplasmic reticulum (Fig. 2). These islets were distributed haphazardly in the cytoplasm and usually contained some rosettes of glycogen. At low magnification, the juxtaposition of the areas of dense and loose smooth endoplasmic reticulum created a 'pepper and salt' appearance of the cytoplasm. The number of hepatocytes affected varied from one patient to another, from one to four cells out of five. The higher incidence was found in one of the patients receiving $20 \mathrm{mg} / \mathrm{kg}$ of the antibiotic.
After seven days of treatment the altered pattern of distribution of the smooth endoplasmic reticulum was observed in four out of five hepatocytes. No changes were observed at the level of other cell organelles or at the level of the cell membrane.

\section{Discussion}

The administration of rifampicin induces an increase in the amount of smooth endoplasmic reticulum in guinea-pig hepatocytes. This increase is evident at the second day, is maximum at the fifth day, and persists at the tenth day of treatment. It is similar to that observed after the administration of various drugs, the prototype of which is phenobarbital (Remmer and Merker, 1963, 1965). The substances capable of inducing similar changes in animal liver have been recently reviewed (Stenger, 1970). This increase in the smooth endoplasmic reticulum is considered as a morphological expression of the induction of drug-metabolizing enzymes present in 
the endoplasmic reticulum. However, some exceptions are known (Stenger, 1970). In human liver, the evidence for such a link between the biochemical and morphological expression of induction is still scanty. An increase in the amount of smooth endoplasmic reticulum has been said to occur after phenobarbital (Whelton, Krustev, and Billing, 1968; Crigler and Gold, 1969) or alcohol administration (Rubin, Hutterer, and Lieber, 1968; Rubin and Lieber, 1968) but it does not seem that morphological changes are qualitatively or quantitatively similar to those observed in animals.

Rifampicin is taken up by the liver and high concentrations of the antibiotic are found in bile and urine (Furesz, 1970). The rifampicin in bile is partly in the form of desacetyl-rifampicin and the relative amount of this compound in the bile gradually increases after administration of the antibiotic (Furesz, 1970). This transformation of rifampicin is also a process of detoxification which is likely to occur at the level of the endoplasmic reticulum; in fact, binding of the drug to microsomes was shown with ${ }^{14} \mathrm{C}$-labelled rifampicin (Riess, Schmid, Keberle, Dettli, and Spring, 1969). Moreover, the high lipophilic properties of rifampicin (Curci, Ninni, and Fabbrocini, 1970) make it likely that the membranes of the endoplasmic reticulum will become involved. The increase in the amount of smooth endoplasmic reticulum which we have observed may support the hypothesis of an enhancement of drug-metabolizing enzymes induced by rifampicin. The extent and the selectivity of this enhancement are still not known.

These findings provide an opportunity to make a comparative study of the expression of induction in man and in animals. Observations made, especially on rats, have often been arbitrarily extended to human subjects. However, neither the metabolism of drugs nor the morphology can be said to be identical in various animal species including man. The particular features of human liver ultrastructure have recently been described (Schaffner and Popper, 1969; Ma and Biempica, 1971; Jezequel and Orlandi, 1972) with emphasis on the diffuse microvacuolar appearance of the endoplasmic reticulum (Ma and Biempica, 1971; Jezequel and Orlandi, 1972) and on the intralobular variations of ultrastructure (Ma and Biempica, 1971). There is no doubt that omitting the study of normal human liver has been a source of some false interpretations. Due to the extent of the smooth endoplasmic reticulum in normal conditions, any diffuse increase in amount is indeed difficult to estimate. The irregular pattern of proliferation of the smooth endoplasmic reticulum seems up to now peculiar to the human liver. The 'pepper and salt' appearance observed after the administration of rifampicin differs from the extensive diffusion observed in guinea-pigs. However, it is worth remembering that the metabolic pattern of rifampicin in man is more similar to that in guinea-pigs than in rats and above all in dogs (Tenconi and Beretta, 1970). Such a difference in the pattern of proliferated smooth endoplasmic reticulum was also seen in rat liver and in human liver after the administration of triacetyloleandomycin (Jezequel and Orlandi, 1972). This morphological difference is probably related to the basic structural dissimilarity.

\section{References}

Acocella, G., and Billing, B. H. (1965). The effect of Rifamycin SV on bile pigment excretion in rats. Gastroenterology, 49, 526-530.

Acocella, G., Nicolis, F. B., and Tenconi, L. T. (1965). The effect of an intravenous infusion of Rifamycin SV on the excretion of bilirubin, bromosulphalein and indocyanine green in man. Gastroenterology, 49, 521-525.

Crigler, J. F., Jr., and Gold, N. I. (1969). Effect of sodium phenobarbital on bilirubin metabolism in antinfant with congenital, nonhemolytic unconjugated hyperbilirubinemia, and kernicterus. J. clin. Invest., 48, 42-55.

Curci, G., Ninni, A., and Fabbrocini, V. (1970). Ricerche sul legame farmacoproteico e sul metabolismo della Rifampicina. Rif. Med., 8, 1-18.

Curci, G., Ninni, A., and Iodice, F. (1969). Quelques considérations sur la pharmacocinétique de la Rifampicine. Acta tuberc. pneumol. belg., 60, 276-287.

Furesz, S. (1970). Chemical and biological properties of Rifampicin. Antibiot. and Chemother., 16, 316-351.

Jézéquel, A. M., and Orlandi, F. (1972). Fine morphology of the liver as a parameter of clinical pharmacology. In Liver and Drugs, edited by F. Orlandi and A. M. Jézéquel. Academic Press, London and New York.

Keberle, H., Schmid, K., and Meyer-Brunot, H. G. (1968). The metabolic fate of Rimactane in the animals and in man. In A Symposium on Rimactane, pp. 20-28. CIBA Ltd, Basle.

Remmer, H., and Merker, J. (1963). Drug-induced changes in the liver endoplasmic reticulum; association with drug-metabolizing enzymes. Science, 142, 1657-1658.

Ma, H. M., and Biempica, L. (1971). The normal human liver cell: cytochemical and ultrastructural studies, Amer. J. Path., 62, 353-390.

Remmer, H., and Merker, H. J. (1965). Effect of drugs on the formation of smooth endoplasmic reticulum and drug-metabolizing enzymes. Ann. N.Y. Acad. Sci., 123, 79-97.

Riess, W., Schmid, K., Keberle, H., Dettli, L., and Spring, P. (1969). Pharmacokinetics studies in the field of Rifamycins. In Proceedings of the 6th International Congress on Chemotherapy, Tokyo, pp. $80-88$.

Rubin, E., Hutterer, F., and Lieber, C. S. (1968). Ethanol increases hepatic smooth endoplasmic reticulum and drug-metabolizing enzymes. Science, 159, 1469-1470.

Rubin, E., and Lieber, C. S. (1968). Hepatic microsomal enzymes in man and rat. Induction and inhibition by ethanol. Science, 162, 690-691.

Schaffner, F., and Popper, H. (1969). Electron microscopy of the Liver. In Diseases of the Liver, 3rd ed., edited by L. Schiff, pp. 50-83. Lippincott, Philadelphia.

Stenger, R. J. (1970). Organelle pathology of the liver. The endoplasmic reticulum. Gastroenterology, 58, 554-574.

Tenconi, L. T., and Beretta, E. (1970). Urinary and biliary metabolites of Rifampicin in different animal species. In The Problems of Species Differences and Statistics in Toxicology (Proc. Europ. Soc. for Study of Drug Toxicity, Vol. II ; Excerpta Med. Int. Congr. Ser. No. 198), pp. 80-85. Excerpta Medica, Amsterdam.

Whelton, M. J., Krustev, L. P., and Billing, B. H. (1968). Reduction in serum bilirubin by phenobarbital in adult unconjugated hyperbilirubinemia. Amer. J. Med., 45, 160-164. 